\title{
AS HABILIDADES DE LEITURA AVALIADAS PELO PISA E PELA PROVA BRASIL: REFLEXÕES PARA SUBSIDIAR O TRABALHO DO PROFESSOR DE LINGUA PORTUGUESA
}

\author{
READING ABILITIES FOCUSED ON IN THE PISA AND IN PROVA BRASIL: REFLECTIONS TO OFFER \\ SUPPORT TO THE PORTUGUESE LANGUAGE TEACHER WORKING \\ LAS HABILIDADES DE LECTURA EVALUADAS POR EL PISA Y POR LA PRUEBA BRASIL: REFLEXIONES \\ PARA SUBSIDIAR EL TRABAJO DEL PROFESOR DE LENGUA PORTUGUESA
}

\author{
Maria Aparecida Garcia Lopes-Rossi* \\ Orlando de Paula \\ Universidade de Taubaté - UNITAU, Taubaté, BR
}

\begin{abstract}
RESUMO: Este artigo tem o objetivo de descrever as principais características da avaliação de leitura do Programa Internacional de Avaliação de Estudantes - PISA - e compará-las às da Prova Brasil. Essa comparação se justifica porque professores de Língua Portuguesa veem-se diante de dados desanimadores sobre a proficiência leitora dos alunos e em dúvida sobre a natureza da avaliação do PISA, que tem enorme repercussão na mídia. Os resultados desta pesquisa revelam que muitas das habilidades de leitura focadas pelo PISA são semelhantes às cobradas pela Prova Brasil. Conclui-se que o conhecimento dessas exigências pode subsidiar o professor para práticas de leitura mais eficientes em sala de aula, fundamentadas em pressupostos teóricos relativos ao conceito bakhtiniano de gênero discursivo e em uma concepção sociocognitiva de leitura.

PALAVRAS-CHAVE: avaliação; leitura; ensino de Língua Portuguesa; gêneros discursivos.
\end{abstract}

ABSTRACT: The aim of this article is to describe the main features of the reading evaluation of the International Program of Student Assessment (PISA) and to compare them to the main features of the Prova Brasil. This comparison is justified by the fact that Portuguese teachers have to face discouraging data from students' reading proficiency and are also unsure of the nature of PISA's evaluation, which has great media repercussion. The results of this research show that many of the reading abilities focused on in the PISA are similar to the ones focused on Prova Brasil. We conclude that the knowledge of these demands can provide teachers with more efficient reading practices in the classroom based on the bakthinian concept of discursive genre and the sociocognitive concept of reading.

KEYWORDS: assessment; reading; Portuguese language teaching; discourse genre.

RESUMEN: Este artículo tiene el objetivo de describir las principales características de la evaluación de lectura del Programa Internacional de Evaluación de Estudiantes - PISA - y compararlas a las de la Prueba Brasil. Esa comparación se justifica porque profesores de Lengua Portuguesa se encuentran entre datos abrumadores sobre la suficiencia lectora de los alumnos y con dudas sobre la naturaleza de la evaluación del PISA, que tiene una enorme repercusión en los medios. Los resultados de esta investigación revelan que muchas de las habilidades de lectura centradas en el PISA se asemejan a las que son cobradas en la Prueba Brasil. Se concluye que el conocimiento de esas exigencias puede subsidiar al profesor para prácticas de lectura más eficaces en el aula, fundamentadas en supuestos teóricos relativos al concepto bakhtiniano de género discursivo y en una concepción sociocognitiva de lectura.

PALABRAS-CLAVE: evaluación; lectura; enseñanza de Lengua Portuguesa; géneros discursivos.

\section{INTRODUÇÃO}

Este artigo tem por objetivo descrever as principais características da avaliação de leitura do Programa Internacional de Avaliação de Estudantes - PISA - e compará-las às da Prova Brasil. ${ }^{1}$ Essa análise e comparação se justificam porque os professores de Língua Portuguesa, a cada divulgação dos resultados da avaliação de leitura do PISA, veem-se diante de dados desanimadores sobre a proficiência leitora de alunos brasileiros e cercados de dúvidas sobre a natureza dessa avaliação, que não é aplicada em todas as escolas brasileiras, mas tem enorme repercussão na mídia. A Prova Brasil, por ser de âmbito nacional, é mais conhecida dos professores, embora ainda careça de análises mais aprofundadas.

\footnotetext{
*Email: lopesrossi@uol.com.br.

'Esta pesquisa desenvolveu-se no âmbito do Projeto Observatório da Educação/UNITAU 2011 - 2014 "Competências e habilidades de leitura: da reflexão teórica ao desenvolvimento e aplicação de propostas didático-pedagógicas”, n 23038010000201076, financiado por CAPES/INEP. Participaram dos estudos sobre esse tema a Profa. Ms. Angela P. Berbare e os bolsistas Alessandra Ribeiro de Jesus, Ana Flávia Paes, Graziela Grand Champ dos Santos, Mariana de Assis Sene Rico, Nelson de Jesus Neto, Priscila Moreira Pereira.
} 
A prova do PISA avalia a proficiência em leitura dos alunos pelas mesmas habilidades de leitura cobradas na Prova Brasil (BRASIL, 2008)? PISA e Prova Brasil são avaliações semelhantes? Um trabalho de leitura que busque desenvolver habilidades de leitura que satisfaçam as exigências de uma prova automaticamente prepara o aluno para as exigências da outra prova? Quais os principais fundamentos teóricos para atividades de leitura em sala de aula? Respostas a essas perguntas podem subsidiar melhor o trabalho do professor de Língua Portuguesa interessado em práticas de leitura mais promissoras e embasadas teoricamente. É o que se apresenta nas seções a seguir, a partir da análise qualitativa de documentos relativos ao PISA e à Prova Brasil, fundamentada teoricamente no conceito bakhtiniano de gênero discursivo e na concepção de leitura como uma atividade sociocognitiva.

\section{INFORMAÇÕES GERAIS SOBRE A PROVA DO PISA}

O Programa Internacional de Avaliação de Estudantes - PISA -, do inglês Programme for International Student Assessment, é um programa de avaliação de habilidades e conhecimentos de alunos, desenvolvido e coordenado internacionalmente pela Organização para Cooperação e Desenvolvimento Econômico (OCDE). Fornece indicadores para avaliação da qualidade do ensino dos países participantes, possibilitando relacionar o desempenho dos alunos a variáveis demográficas, socioeconômicas e educacionais por meio da aplicação de questionários específicos para os alunos e para as escolas. De acordo com o Instituto Nacional de Estudos e Pesquisas Anísio Teixeira (INEP), os resultados podem ser interpretados de acordo com o contexto de cada país e utilizados como instrumento de trabalho para a definição de políticas educativas, visando a "tornar mais efetiva a formação dos jovens para a vida futura e para a participação ativa na sociedade" (INEP, 2011, p. 01). Essa avaliação é aplicada de forma amostral, conforme critérios da OCDE, a alunos na faixa dos 15 anos de idade, matriculados da $7^{\text {a }}$ série $\left(8^{\circ}\right.$ ano) em diante, até o final do Ensino Médio.

O principal foco do PISA são as questões de políticas públicas voltadas à Educação de cada país participante. São elas:

Até que ponto os alunos próximos do término da educação obrigatória adquiriram conhecimentos e habilidades essenciais para a participação efetiva na sociedade? As escolas estão preparando os alunos para enfrentarem os desafios do futuro? Quais estruturas e práticas educacionais maximizam oportunidades para alunos que vêm de contextos pouco privilegiados? Qual a influência da qualidade dos recursos das escolas nos resultados alcançados pelos alunos? (INEP, 2001, p. 08).

De acordo com o INEP (2011, p. 01), o objetivo principal do PISA é

produzir indicadores que contribuam para a discussão da qualidade da educação ministrada nos países participantes, de modo a subsidiar políticas de melhoria da educação básica. A avaliação procura verificar até que ponto as escolas de cada país participante estão preparando seus jovens para exercerem o papel de cidadãos na sociedade contemporânea.

O PISA é organizado tendo como base um modelo dinâmico de aprendizagem, em que a aquisição de novos conhecimentos e habilidades deve contribuir para que os jovens possam ter êxito em um mundo que está em constante transformação. De acordo com esse modelo, "para serem aprendizes efetivos por toda a vida, os jovens precisam de uma base sólida em domínios-chave, e devem ser capazes de organizar e gerir seu aprendizado, o que requer consciência da própria capacidade de raciocínio e de estratégias e métodos de aprendizado". (INEP, 2011 , p. 01).

As avaliações do PISA ocorrem de três em três anos e abrangem três áreas do conhecimento: Leitura, Matemática e Ciências. Em cada ano de realização, o foco principal se detém sobre uma dessas áreas: em 2000, foi em Leitura; em 2003, em Matemática; em 2006, em Ciências; em 2009, em Leitura. Segundo o site do INEP (www.inep.gov.br), para 2012 e 2015 estão previstos foco em Matemática e em Ciências, respectivamente. Essas três áreas são especialmente chamadas de "letramento" em Leitura, Matemática e Ciências, referindo-se o termo "letramento" à extensão dos conhecimentos e competências que são avaliados. Nesse sentido, letramento em Leitura "consiste em compreender, utilizar, refletir sobre e envolver-se com textos, a fim de alcançar objetivos pessoais, construir conhecimento, desenvolver o potencial individual e participar ativamente da sociedade." (INEP, 2010, p. 01). 
Para a realização da prova de 2009, foram consideradas as seguintes condições: amostra definida internacionalmente, tendo como base os alunos nascidos em 1993; provas traduzidas de dois diferentes idiomas; monitoramento internacional e independente. Junto com a prova, os alunos responderam a um questionário socioeconômico. Participaram 65 países, dentre os quais 34 membros da OCDE, totalizando 470 mil estudantes. O Brasil participa do PISA desde 1998, data de sua primeira edição, sob coordenação do INEP. Em 2009, teve 20 mil alunos participantes.

Os resultados das quatro últimas participações do Brasil (2000, 2003, 2006 e 2009) mostram uma pequena melhora no desempenho dos alunos nas provas de Leitura, Matemática e Ciências, de acordo com dados divulgados pelo INEP. Em comparação com outros países, no entanto, ainda não se pode considerar que esses resultados sejam ideais. O resultado geral do Brasil corresponde a 401 pontos, e a média geral dos países integrantes da OCDE corresponde a 496 pontos. Especificamente em leitura, o desempenho do Brasil em 2009 - 412 pontos - também está abaixo da média geral dos países integrantes da OCDE, que é 493 pontos. Observando os resultados da proficiência leitora dos alunos brasileiros em relação às unidades da Federação, observam-se algumas variações, sendo que o Distrito Federal, Santa Catarina e Rio Grande do Sul foram as que apresentaram os melhores resultados - 442,6 a maior pontuação -, e Alagoas, Maranhão e Piauí foram as que apresentaram os piores resultados - 380 a menor pontuação.

A repercussão na mídia sobre o desempenho do Brasil na Prova de Leitura do PISA foi grande e em tom de crítica à educação brasileira, principalmente às escolas públicas (GOIS, PINHO, 2007; CIEGLINSKI, 2010; OKADA, 2010; TARGINO, 2010; OEI, 2010), tendo sido ressaltada a $53^{\text {a }}$ classificação do país no total de 65 países, atrás de México, Colômbia e Uruguai. Contudo, o Brasil teve o segundo maior crescimento entre os 65 países participantes, e a OCDE cita como causas o aumento da relação PIB (Produto Interno Bruto) e o investimento em educação. O blog do UOL Educação atribuiu esse crescimento à combinação de maior investimento, instrumentos de avaliação e melhores salários para professores. Os sites, revistas e blogs consultados, porém, implícita ou explicitamente, concluem que não é vantagem valorizar um pequeno crescimento face ao fracasso do Brasil na prova, em comparação aos outros países.

\section{OS NÍVEIS DE PROFICIÊNCIA EM LEITURA DO PISA, CONTEÚDO, COMPETÊNCIAS E CONTEXTO}

Para avaliar a capacidade de os alunos usarem seus conhecimentos e habilidades, tendo como base um modelo dinâmico de aprendizagem, o PISA estabeleceu uma matriz de referência a partir de conhecimentos associados a habilidades para contemplar os resultados apresentados pelos alunos no final do processo de escolarização básica. Os seis "níveis de alfabetismo em leitura" ou "níveis de letramento" (até 2006 eram 5 níveis) que compõem essa matriz partem da definição de leitura "como um processo 'ativo', que implica não apenas a capacidade para compreender um texto, mas a capacidade de refletir sobre ele e de envolver-se com o texto, a partir das ideias e experiências próprias" (INEP, 2010, p. 1).

A proficiência em leitura, que consiste no uso e na compreensão de textos escritos, assim como na reflexão sobre esses textos, "com vistas a alcançar objetivos pessoais, desenvolver o conhecimento e potencial individuais visando à participação plena na vida em sociedade” (INEP, 2001, p. 29), é testada em tarefas que envolvem três competências/domínios: identificação e recuperação de informação, interpretação e reflexão, desdobradas nos seis níveis de proficiência. Diferentes tipos de textos - contínuos, não contínuos, mistos e múltiplos -, como serão descritos mais adiante, são utilizados na prova.

O quadro 1, a seguir, adaptado do quadro Leitura (INEP, 2001; 2011), apresenta os níveis de proficiência definidos pelo PISA em termos de habilidades, com a respectiva pontuação indicativa do grau de dificuldade do item. Os itens da prova classificados em mais de seiscentos pontos são considerados muito difíceis; os classificados como inferiores a quatrocentos pontos são considerados mais fáceis. Para o PISA, a expectativa é que os alunos alcancem os níveis 3 ou 2. Uma vez que as análises dos resultados das últimas avaliações mostraram que em muitos países muitos estudantes ficaram abaixo do nível 1, o PISA subdividiu o nível 1 em $1 \mathrm{~A}$ e $1 \mathrm{~B}$.

Os seis níveis de desempenho são "baseados na classificação da pontuação associada às habilidades que os estudantes devem possuir para alcançar a pontuação correspondente" (INEP, 2011, p. 1). No entanto, o PISA ressalta que a ideia principal da avaliação não é avaliar indivíduos, mas avaliar o sistema educacional de cada país participante. O exame verifica a operacionalização de esquemas cognitivos em termos de 
conteúdo (conhecimentos que os alunos precisam aprender), competências (aplicação dos conteúdos) e contextos (situação em que são aplicados).

\begin{tabular}{|c|c|}
\hline $\begin{array}{l}\text { Níveis de } \\
\text { proficiência } \\
\text { em leitura }\end{array}$ & Habilidades \\
\hline $\begin{array}{l}\text { Nível } \mathbf{1 B} \\
\text { (limite inferior } \\
262 \text { ) }\end{array}$ & $\begin{array}{l}\text {-localizar apenas uma informação explícita em um texto Fcurto e simples. } \\
\text {-fazer conexões simples entre trechos de informação colocados lado-a-lado } \\
\text { (tarefas de interpretação). }\end{array}$ \\
\hline $\begin{array}{l}\text { Nível } \mathbf{1 A} \\
\text { (limite inferior } \\
335 \text { ) }\end{array}$ & $\begin{array}{l}\text {-localizar uma ou mais partes independentes de uma informação explícita. } \\
\text {-reconhecer o tema principal ou a intenção do autor. } \\
\text {-fazer uma conexão simples entre a informação no texto e o conhecimento cotidiano. }\end{array}$ \\
\hline $\begin{array}{l}\text { Nível } 2 \text { (limite } \\
\text { inferior } 407 \text { ) }\end{array}$ & $\begin{array}{l}\text {-localizar informações, que podem ser inferidas em um texto. } \\
\text {-reconhecer a ideia central de um texto, compreender as relações ou explicar o } \\
\text { significado de uma parte do texto (inferências simples). } \\
\text {-comparar e diferenciar tendo por base um único aspecto do texto. } \\
\text {-fazer comparações ou diversas conexões entre o texto e outros conhecimentos, a } \\
\text { partir de experiências pessoais (tarefas de reflexão). }\end{array}$ \\
\hline $\begin{array}{l}\text { Nível } 3 \text { (limite } \\
\text { inferior } 480 \text { ) }\end{array}$ & $\begin{array}{l}\text {-localizar e reconhecer as relações entre várias informações em um texto. } \\
\text {-integrar várias partes de um texto a fim de identificar a ideia principal, compreender } \\
\text { relações ou explicar o significado de uma palavra ou frase (tarefas de interpretação). } \\
\text {-fazer conexões, comparações e explicações, ou avaliar um aspecto do texto (tarefas } \\
\text { de reflexão). }\end{array}$ \\
\hline $\begin{array}{l}\text { Nível 4 (limite } \\
\text { inferior } 553 \text { ) }\end{array}$ & $\begin{array}{l}\text {-localizar e organizar várias informações relacionadas em um texto. } \\
\text {-interpretar o significado de nuances de linguagem em uma parte do texto, levando } \\
\text { em consideração o texto como um todo. } \\
\text {-compreender e aplicar categorias em um contexto pouco familiar (tarefas de } \\
\text { interpretação). } \\
\text {-utilizar conhecimento formal ou público para levantar hipóteses e avaliar } \\
\text { criticamente um texto (tarefas de reflexão). } \\
\text {-demonstrar compreensão exata de textos complexos cujo conteúdo pode não ser } \\
\text { familiar. }\end{array}$ \\
\hline $\begin{array}{l}\text { Nível 5 (limite } \\
\text { inferior 626) }\end{array}$ & $\begin{array}{l}\text {-localizar e organizar várias partes de informações contidas no texto, inferindo a(s) } \\
\text { informação(ões) relevante(s). } \\
\text {-fazer avaliação crítica, levantamento de hipóteses, com base em conhecimento } \\
\text { especializado (tarefas de reflexão). } \\
\text {-demonstrar uma compreensão completa e detalhada de um texto cujo conteúdo ou } \\
\text { forma não seja familiar (tarefas de interpretação e reflexão). }\end{array}$ \\
\hline $\begin{array}{l}\text { Nível } 6 \text { (limite } \\
\text { inferior } 708 \text { ) }\end{array}$ & $\begin{array}{l}\text {-fazer múltiplas inferências, comparações e contraste. } \\
\text {-demonstrar completa e detalhada compreensão de um ou mais textos, integrando } \\
\text { informações de mais de um texto. } \\
\text {-trabalhar com ideias desconhecidas, na presença de informações contrastantes, que } \\
\text { possam gerar categorias abstratas de interpretação. } \\
\text {-levantar hipóteses ou avaliar criticamente um texto complexo ou um tópico que não } \\
\text { lhe seja familiar, considerando vários critérios e perspectivas e aplicando sofisticados } \\
\text { conhecimentos. } \\
\text { Obs.: Nesse nível, exige-se precisão de análise e atenção cuidadosa aos detalhes } \\
\text { imperceptíveis dos textos. }\end{array}$ \\
\hline
\end{tabular}

Quadro 1 - Níveis de proficiência em leitura e habilidades avaliados pelo PISA.

Fonte: www.inep.gov.br/internacional/pisa/PISA2000.pdf. 
Em se tratando do conteúdo, o PISA utiliza diferentes tipos e formatos de textos. Quanto aos formatos, os textos são denominados contínuos (compostos por frases e parágrafos), não contínuos (apresentam-se como gráficos, mapas, formulários, diagramas, tabelas, listas etc.), mistos (compostos por textos contínuos e não contínuos) e múltiplos (dois ou mais textos diferentes justapostos). Quanto aos tipos, podem ser descritivos, narrativos, expositivos, argumentativos e prescritivos ou instrucionais. Observa-se que essa tipologia baseia-se na tradicional classificação dos textos por seus modos de organização do discurso, como explicam Silva (1999) e Marcuschi (2002), e não no conceito bakhtiniano de gênero discursivo.

A concepção enunciativo-discursiva concebe a linguagem como um fenômeno sócio-histórico, de acordo com Bakhtin (1992), não dissociado de seus falantes e de seus atos, das esferas sociais, dos valores ideológicos. Os atos de linguagem se realizam por meio de enunciados orais e escritos, produzidos nas inúmeras esferas sociais, sendo cada enunciado reconhecido e nomeado pelos falantes da língua por suas características típicas e constitutivas, quais sejam: aspectos sócio-comunicativos (condições de produção e de circulação, propósito comunicativo, temática), elementos composicionais verbais e não verbais e estilo. Cada enunciado é uma realização de um gênero discursivo, unidade real e concreta da comunicação humana e, portanto, toda a interação humana se dá por meio desses gêneros.

Um gênero discursivo escrito compõe-se não apenas por elementos verbais. Minimamente, apresenta uma modalidade de linguagem não verbal representada pela diagramação do texto. Frequentemente cores, fotos, infográficos, elementos gráficos diversos compõem os gêneros discursivos escritos, uma propriedade denominada multimodalidade (DIONÍSO, 2005). Com base nos trabalhos de pesquisadores da Universidade de Genebra, dentre os quais Dolz e Schneuwly (1996), os PCN (BRASIL, 1998) sugerem que os gêneros discursivos das diversas esferas sociais (literária, jornalística, publicitária, comercial, de divulgação científica, entre outras) sejam tomados como objetos privilegiados no ensino de língua portuguesa. Assim, são sugeridos para atividades de leitura gêneros como: conto, fábula, poema, notícia, reportagem, artigo de opinião, anúncio publicitário, carta, recibo, verbete de enciclopédia, entre muitos outros gêneros discursivos que possam interessar aos alunos. Visa-se à ampla e rica abordagem das condições de produção de linguagem, situações de comunicação e relações dialógicas constitutivas dos enunciados para que o aluno amplie seu domínio ativo do discurso nas diversas situações comunicativas.

Na perspectiva bakhtiniana, destacam Faraco (2003) e Fiorin (2006), a produção do enunciado vincula-se às condições e coerções da situação de interação, da língua, do gênero, sendo, pois, a situação social constitutiva dos gêneros discursivos. A vinculação dos enunciados ao contexto sócio-histórico-ideológico, por meio da relação dialógica que cada produção de linguagem (enunciado) estabelece com outros enunciados, é fundamental para orientar as práticas de leitura de gêneros discursivos.

Embora o PISA não mencione o conceito de gênero discursivo, observa-se que, para que o aluno desenvolva sua competência leitora nos diferentes formatos de texto utilizados nessa avaliação, deverá ser leitor de gêneros discursivos de diversas esferas de atuação social.

Três competências norteiam o PISA. A primeira - identificar e recuperar informação - consiste em revisar, buscar, localizar e selecionar a informação relevante, identificar os elementos essenciais de uma mensagem, comparar a informação contida na pergunta com outras informações literais no texto e utilizá-la para encontrar a informação que foi solicitada. A segunda - desenvolver interpretação - exige uma compreensão mais completa dos alunos. Entre as tarefas, os alunos devem comparar e contrastar informações, integrando dois ou mais trechos do texto; elaborar uma interpretação global do texto, identificar o tema, compreender a mensagem, deduzir a intenção do autor e interpretar uma parte do texto. A terceira - refletir sobre e analisar o conteúdo ou a forma - exige o conhecimento de elementos tais como a estrutura textual, o gênero e o tom. Solicita-se que os alunos detectem nuances na escolha lexical, apontem evidências ou argumentos externos ao texto, avaliem a relevância de fragmentos de informação e os comparem com regras morais ou estéticas, identifiquem informações usadas como argumentos pelo autor e avaliem a validade das informações do texto. Consideradas mais complexas, as tarefas desta competência incluem a "determinação da utilidade de um texto para conseguir um propósito determinado e a identificação do uso que o autor faz de determinadas estruturas textuais para conseguir um objetivo específico” (INEP, 2011, p. 02).

Por sua vez, contexto está relacionado a quatro situações de leitura conforme a finalidade para a qual o texto foi elaborado e o uso a que ele se destina: leitura para o uso pessoal, leitura para o uso público, leitura para a educação e leitura para o trabalho. A primeira refere-se aos interesses dos indivíduos e à manutenção e desenvolvimento de relações com outras pessoas, como, por exemplo, cartas pessoais, textos de ficção, 
biografias e informativos lidos por curiosidade, prazer ou recreação. A segunda está ligada à participação em atividades sociais e relaciona-se a documentos oficiais, informações sobre eventos públicos e notícias de interesse da coletividade. Em geral, essas tarefas estão associadas a contatos mais ou menos anônimos com outras pessoas. A terceira situação, leitura para a educação, está relacionada à aquisição de informações como parte de uma tarefa de aprendizagem mais ampla. Neste caso, "os materiais são escolhidos pelo leitor, mas indicados pelo professor. O conteúdo normalmente é sugerido especificamente em função dos objetivos de instrução". (INEP, 2011, p. 04). A quarta situação, leitura para o trabalho, embora não necessária para a maior parte dos jovens de 15 anos, está normalmente relacionada ao desenvolvimento de uma tarefa imediata e pode contribuir para incluí-lo no mundo do trabalho, do qual fará parte num futuro próximo.

As competências e situações de leitura citadas no documento do PISA, além dos objetivos gerais da avaliação já mencionados, evidenciam que a concepção de leitura subjacente a essa avaliação é compatível com uma abordagem sociocognitiva de leitura, pela qual, como explicam Koch e Elias (2006), leitura é:

[...] uma atividade interativa altamente complexa de produção de sentidos, que se realiza evidentemente com base nos elementos lingüísticos presentes na superfície textual e na sua forma de organização, mas requer a mobilização de um vasto conjunto de saberes no interior do evento comunicativo. (p. 10-11)

A compreensão é, portanto, mais do que uma atividade cognitiva, “[ [..] é uma atividade de seleção, reordenação, reconstrução, em que certa margem de criatividade é permitida. De resto, a compreensão é uma atividade dialógica que se dá na relação com o outro.”, afirma Marcuschi (2008, p. 256). Para esse autor, ainda, "Compreender bem um texto não é uma atividade natural nem uma herança genética [...] exige habilidade, interação e trabalho.” (p. 229-230). Nessa perspectiva, compreende-se que é possível que o leitor desenvolva suas habilidades de leitura mediante práticas escolares devidamente fundamentadas teoricamente. $\mathrm{O}$ conhecimento das habilidades exigidas pelas diferentes avaliações a que os alunos são submetidos contribui para o planejamento dessas práticas.

\title{
Exemplos de questões da prova do Pisa
}

A prova do PISA é apresentada aos estudantes em forma de caderno de questões composto por questões abertas, para as quais o aluno tem que elaborar respostas dissertativas e questões múltipla-escolha, baseadas na Teoria de Resposta ao Item (TRI), metodologia que sugere "formas de representar a relação entre a probabilidade de um indivíduo dar uma certa resposta a um item e seus traços latentes, proficiências ou habilidades na área de conhecimento avaliada." (ANDRADE; TAVARES; VALLE, 2000, p. 3). A TRI é utilizada no Brasil, desde 1995, nas avaliações do Saeb, e, desde 2009, no Exame Nacional do Ensino Médio (ENEM). Essa metodologia permite a comparação entre estudantes de diferentes populações, desde que as provas apresentem alguns itens comuns, ou iguais.

Os alunos têm cerca de duas horas para responder às questões que envolvem as diferentes habilidades explicitadas no Quadro 1. Abaixo, seguem dois exemplos de questões liberadas da prova do PISA de 2009 (INEP, 2011), cujo foco foi leitura. Após as alternativas, apresentam-se os códigos utilizados para a correção equivalentes à resposta correta, resposta parcialmente correta, resposta incorreta, resposta em branco.

Exemplo1:

\section{O AVARENTO E SUA BARRA DE OURO}

\author{
Fábula de Esopo
}

Um avarento vendeu tudo o que tinha e comprou uma barra de ouro, que enterrou em um buraco, perto de um velho muro. Diariamente, ele ia olhar o seu tesouro. Um dos seus empregados, observando o que ele fazia, decidiu espionar aquele vai-e-vem. Ele logo descobriu o segredo do tesouro escondido, desenterrou a barra de ouro e levou-a consigo. Quando o avarento foi fazer a sua inspeção, viu o buraco vazio e começou a se lamentar e a arrancar os cabelos. Um vizinho, vendo-o nesse estado de tanta dor e compreendendo o que afligia o avarento, disse-lhe: "Por que ficar assim tão desolado? Basta pôr uma pedra no buraco onde estava a barra de ouro e imaginar que ela ainda está lá. Pois, mesmo quando o ouro estava lá, você não fazia uso dele.”. 


\section{Questão 2: O AVARENTO}

Qual é a principal mensagem desta história?

A. Não acumule riquezas que possam ser roubadas.

B. Confiar nos outros é um erro.

C. Não utilizar o que se possui equivale a não possuir nada.

D. Não se queixe de coisas que não podem ser modificadas.

\section{CORREÇÃO}

OBJETIVO DA QUESTÃO: Integrar e interpretar: Entender o sentido geral de um texto.

Identificar a idéia principal de uma fábula.

\section{Crédito completo}

Código 1: C. Não utilizar o que se possui equivale a não possuir nada.

\section{Nenhum crédito}

Código 0: Outras respostas.

Código 9: Em branco.

\section{Questão 6: O AVARENTO}

Por que o avarento enterrou o seu ouro?

\section{CORREÇÃO:}

OBJETIVO DA QUESTÃO: Refletir e avaliar: Refletir sobre o conteúdo de um texto e avaliá-lo. Emitir uma hipótese sobre a razão das ações de um personagem, associando conhecimentos prévios com informações do texto.

\section{Crédito completo}

Código 1: Identifica o fato de que o avarento queria guardar o ouro em lugar seguro OU que estava com medo.

Para esconder o ouro.

Ele pensou que se o escondesse, ninguém poderia roubar dele.

Ele queria que estivesse em lugar seguro.

É claro que o homem era meio maluco e pensava que o ouro estaria mais seguro se estivesse enterrado do que no banco! [Ignorar a hipótese incorreta segundo a qual os bancos existiam na época em que a fábula foi escrita]

\section{Nenhum crédito}

Código 0: A uma resposta insuficiente ou vaga.

Ele era estúpido.

A uma resposta que indica uma compreensão errada do texto ou que seja implausível ou irrelevante. 
Ele queria roubar o ouro.

Código 9: Em branco.

Observam-se, no exemplo 1, objetivos e créditos das questões que indicam o que se esperava dos alunos: um texto com questões em que as competências "desenvolver interpretação" e "refletir sobre e analisar o conteúdo ou a forma” são exploradas, por meio dos níveis de leitura 2 (questão 2) e 4 (questão 6), respectivamente.

Exemplo 2:

\section{DESTINO BUENOS AIRES}

Assim, os três aviões postais da Patagônia 1, do Chile e do Paraguai regressavam do sul, do oeste e do norte para Buenos Aires. Lá, esperava-se a sua carga para dar a partida, por volta da meia-noite, ao avião da Europa.

Três pilotos, cada um atrás de um capô pesado como uma traineira, perdidos na noite, contemplavam o vôo e, aproximando-se da cidade imensa, desciam lentamente do céu tempestuoso ou calmo, como estranhos camponeses descem da montanha.

Rivière, responsável por toda a operação, passeava de um lado para o outro no campo de pouso de Buenos Aires. Permanecia em silêncio, pois, até a chegada dos três aviões, este dia ainda era assustador para ele. Minuto após minuto, à medida que lhe chegavam os telegramas, Rivière tinha consciência de arrancar algo ao acaso, gradualmente reduzindo o desconhecido e retirando as tripulações da noite, até o litoral.

Um operador dirigiu-se a Rivière para comunicar-lhe uma mensagem vinda pelo rádio:

O avião-correio do Chile avisa que está vislumbrando as luzes de Buenos Aires. Bom. Em pouco tempo, Rivière ouviria o avião: a noite já entregava um deles, assim como um mar, cheio de fluxos e refluxos e de mistério, entrega à praia o tesouro que ficou tanto tempo revolvendo. E, mais tarde, dela seriam recebidos os outros dois.

Então aquela jornada estaria liquidada. Então as equipes esgotadas iriam dormir, substituídas pelas novas equipes. Mas Rivière não teria descanso: o avião-correio da Europa, por sua vez, ia enchê-lo de preocupações. Sempre seria assim. Sempre.

(Antoine de Saint-Exupéry. Vol de Nuit. (C) Éditions Gallimard)

O texto "Destino Buenos Aires" da página anterior foi extraído de um romance escrito em 1931. O romance é baseado na experiência do autor como piloto de avião postal na América do Sul. Com base nesse trecho, responda às seguintes questões:

\section{Questão 1: DESTINO BUENOS AIRES}

Em que período do dia desenrola-se este relato? Com base no texto, justifique sua resposta.

\section{DESTINO BUENOS AIRES: CORREÇÃO 1}

OBJETIVO DA QUESTÃO: Integrar e interpretar: Desenvolver uma interpretação.

Usar uma ou mais referências do texto para identificar quando se desenrola a ação numa narrativa.

\section{Crédito completo}

Código 2: Indica que os vôos acontecem à noite ou à noitinha (mas nem à meia-noite nem depois da meia-noite) E justifica a resposta referindo-se corretamente à informação que consta do texto. Pode interpretar o tex to ou citá-lo diretamente.

À noite, porque é dito "perdidos na noite”.

À noite; está esperando a chegada deles para que o avião da Europa possa partir por volta da meia-noite.

Era à noite, pois “a noite já entregava um deles”.

Antes da meia-noite, porque é a hora em que deve partir o avião da Europa. 
Entre 20 e meia-noite. Sabemos que está escuro, mas que ainda não é meia-noite. É a hora em que o outro avião decola.

Crédito parcial

Código 1: Indica que os vôos acontecem à noite ou à noitinha (mas nem à meia-noite nem depois da meia-noite), mas não justifica a resposta com nenhuma elemento do texto.

À noite.

Nenhum crédito

Código 0: Indica que os vôos aconteceram à meia-noite ou depois da meia-noite.

"Para a partida por volta de meia-noite”. [Citação inapropriada do texto]

"Por volta de meia-noite". [Citação inapropriada do texto]

Depois de meia-noite.

Dá uma resposta insuficiente ou vaga.

Dá uma reposta que indica uma compreensão errada do texto ou que seja implausível ou irrelevante.

De manhã.

À tarde.

Durante o dia.

Às $21 \mathrm{~h}$. [Ou a qualquer outra hora precisa]

Código 9: Em branco.

No exemplo 2, por sua vez, há uma questão mais simples, que avalia a competência "identificar e recuperar informação", por meio do nível de leitura 1A.

\section{OS NÍVEIS DE PROFICIÊNCIA EM LEITURA DA PROVA BRASIL}

A Prova Brasil é uma avaliação desenvolvida pelo INEP/MEC, formada por testes de Língua Portuguesa e de Matemática, além de um questionário socioeconômico. Criada em 2005, objetiva avaliar a qualidade do ensino oferecido pelo sistema educacional brasileiro. É uma avaliação censitária para alunos de $4^{\mathrm{a}}$ e $8^{\mathrm{a}}$ séries do Ensino Fundamental público das redes estaduais, municipais e federais da área urbana do país. Participam escolas com no mínimo 20 alunos matriculados na série avaliada. (BRASIL, 2008).

Pretende-se, com essa prova, retratar a realidade de cada escola, em cada município; contribuir para dimensionar os problemas da educação básica brasileira; e orientar a formulação, a implementação e a avaliação de políticas públicas educacionais que conduzam à formação de uma escola de qualidade. As médias de desempenho nessa avaliação, juntamente com as do Sistema Nacional de Avaliação da Educação Básica (SAEB), subsidiam o cálculo do Índice de Desenvolvimento da Educação Básica (IDEB).

As Matrizes de Referência da Prova Brasil (Quadro 2) listam as habilidades de leitura a serem avaliadas em itens denominados "Descritores". São 15 descritores para o $5^{\circ}$ ano e 21 para o $9^{\circ}$ ano, divididos em seis tópicos: Procedimentos de leitura; Implicações do suporte, do gênero e/ou do enunciador na compreensão do texto; Relação entre textos; Coerência e coesão no processamento do texto; Relações entre recursos expressivos e efeitos de sentido; Variação linguística. Reproduziremos e comentaremos os descritores para o $9^{\circ}$ ano por serem os alunos desse ano de faixa etária semelhante à dos alunos que realizam a Prova do PISA. Interessa-nos, portanto, comparar as habilidades de leitura cobradas pelas duas provas, nesse nível.

A análise dessa Matriz de Referência, à luz de pressupostos teóricos sobre gêneros discursivos (BAKHTIN, 1992) e sobre leitura de uma perspectiva sociocognitiva (KOCH, 2005; MARCUSCHI, 2008; LOPESROSSI, 2011), permite que se chegue a várias conclusões a respeito do enfoque que se dá à leitura e sobre problemas conceituais de vários dos descritores.

Os descritores pressupõem o tratamento do texto como um exemplar de um gênero discursivo, como evidenciam as seguintes marcas linguísticas extraídas de alguns descritores: gênero, suporte, propaganda, 
quadrinhos. Nesse sentido, estão em sintonia com os PCN (BRASIL, 1998). Alguns descritores podem ser aplicados a atividades sobre texto de qualquer gênero. São eles: D1, D2, D3, D4, D6, D12, D15, D17, D18 e D19, que, de maneira geral, referem-se à localização de informações explícitas, inferências, elementos de coesão e coerência, identificação de efeitos de sentido decorrentes de recursos vários, identificação da finalidade e do tema do texto.

\begin{tabular}{|c|}
\hline Tópico I. Procedimentos de leitura \\
\hline D1 - Localizar informações explícitas em um texto \\
\hline D3 - Inferir o sentido de uma palavra ou expressão \\
\hline D4 - Inferir uma informação implícita em um texto \\
\hline D6 - Identificar o tema de um texto \\
\hline D14 - Distinguir um fato da opinião relativa e esse fato \\
\hline Tópico II. Implicações do suporte, do gênero e/ou do enunciador na compreensão do texto \\
\hline D5 - Interpretar texto com auxílio de material gráfico diverso (propagandas, quadrinhos, fotos, etc.) \\
\hline D12 - Identificar a finalidade de textos de diferentes gêneros \\
\hline Tópico III. Relação entre textos \\
\hline $\begin{array}{l}\text { D20 - Reconhecer diferentes formas de tratar uma informação na comparação de textos que tratam } \\
\text { do mesmo tema, em função das condições em que ele foi produzido e daquelas em que será recebido }\end{array}$ \\
\hline $\begin{array}{l}\text { D21 - Reconhecer posições distintas entre duas ou mais opiniões relativas ao mesmo fato ou ao } \\
\text { mesmo tema }\end{array}$ \\
\hline Tópico IV. Coerência e coesão no processamento do texto \\
\hline $\begin{array}{l}\text { D2 - Estabelecer relações entre partes de um texto, identificando repetições ou substituições que } \\
\text { contribuem para a continuidade de um texto }\end{array}$ \\
\hline D10 - Identificar o conflito gerador do enredo e os elementos que constroem a narrativa \\
\hline D11 - Estabelecer relação de causa e conseqüência entre partes e elementos do texto \\
\hline $\begin{array}{l}\text { D15 - Estabelecer relações lógico-discursivas presentes no texto, marcadas por conjunções, } \\
\text { advérbios, etc. }\end{array}$ \\
\hline D7 - Identificar a tese de um texto \\
\hline D8 - Estabelecer relação entre a tese e os argumentos oferecidos para sustentá-la \\
\hline D9 - Diferenciar as partes principais das secundárias de um texto \\
\hline Tópico V. Relações entre recursos expressivos e efeitos de sentido \\
\hline D16 - Identificar efeitos de ironia ou humor em textos variados \\
\hline D17 - Identificar o efeito de sentido decorrente do uso da pontuação e de outras notações \\
\hline $\begin{array}{l}\text { D18 - Reconhecer o efeito de sentido decorrente da escolha de uma determinada palavra ou } \\
\text { expressão }\end{array}$ \\
\hline $\begin{array}{l}\text { D19 - Reconhecer o efeito de sentido decorrente da exploração de recursos ortográficos e/ou } \\
\text { morfossintáticos }\end{array}$ \\
\hline Tópico IV. Variação lingüística \\
\hline D13 - Identificar as marc \\
\hline
\end{tabular}

Outros descritores são aplicáveis apenas a alguns gêneros, dependendo de sua organização textual (sua tipologia), como D10, referente apenas a gêneros com estrutura textual narrativa, e D7 e D8, referentes a gêneros com estrutura textual argumentativa clássica. Nesses casos, observa-se uma mistura do conceito de gênero discursivo com o de tipologia textual, o que pode confundir o professor.

A distinção de um fato da opinião relativa a esse fato (D14) é uma habilidade restrita a alguns textos que se refiram a fatos e que apresentem opinião relativa ao fato, implícita ou explicitamente. Essa não é, portanto, uma habilidade aplicável a qualquer texto, embora a opinião relativa a um fato possa ser expressa em gêneros discursivos diversos.

As definições de alguns tópicos e alguns descritores são passíveis de críticas por imprecisão teórica ou pouca abrangência, como é o caso de "Procedimentos de leitura". Os cinco descritores apresentados nesse tópico não abrangem um processo de leitura completo (do reconhecimento inicial do texto à apreciação crítica); os descritores indicam alguns procedimentos de leitura possíveis, mas não suficientes para uma prática de leitura eficiente e proficiente. 
A importante propriedade de variação sociolinguística da língua portuguesa ficou parcialmente reconhecida pelo D13. A habilidade esperada para esse tópico deveria incluir também a identificação de marcas linguísticas que evidenciam elementos da situação de comunicação, como nível de formalidade, época, relações hierárquicas entre os interlocutores, idade e nível de escolaridade dos interlocutores, entre outros.

Embora se conclua que não haja descritor referente a posicionamento crítico do leitor, que alguns descritores deveriam ser reformulados, outros excluídos e novos poderiam ser incluídos, é possível concluir que a Matriz de Referência da Prova Brasil busca englobar habilidades de leitura que vão além da decodificação, que permitem a compreensão de textos de diferentes gêneros discursivos e, ainda, de parte das interações sociais que promovem em seus contextos de produção e de circulação social.

\section{COMPARAÇÃO ENTRE PISA E PROVA BRASIL COMO SUBSÍDIO PARA O TRABALHO DO PROFESSOR}

A comparação das características dos níveis de proficiência do PISA e da Matriz de Referência da Prova Brasil revela muitos pontos em comum. Os níveis de proficiência em leitura cobrados por ambos enfocam habilidades de leitura que vão desde o nível mais básico de identificação e decodificação de informação explícita até os níveis inferenciais mais profundos, possíveis pela operacionalização de esquemas sociocognitivos de leitura desenvolvidos durante a escolarização, a partir de contato com textos dos mais diferentes gêneros discursivos. Em essência, os níveis 1B, 1A, 2, 3 e 4 do PISA correspondem aos apresentados na matriz de referência da Prova Brasil, ainda que vários descritores da Prova Brasil apresentem problemas conceituais e de formulação.

Ambas as provas organizam-se de forma a cobrar - por meio de textos e perguntas referentes a eles - uma proficiência que deve ter sido desenvolvida pelo aluno ao longo de anos de escolaridade. Embora o PISA não mencione o conceito de gênero discursivo, como o fazem as Matrizes de Referência da Prova Brasil, esse se aplica perfeitamente bem às suas exigências. Tem-se apenas uma diferença terminológica entre as duas provas.

A preparação dos alunos para ambas as provas exige que o professor de Língua Portuguesa trabalhe com gêneros discursivos diversos, incluindo textos contínuos (constituídos apenas de material verbal, como artigo de opinião, conto, crônica, carta, bula), textos não contínuos (constituídos de material não verbal, como gráficos, mapas, formulários, diagramas, tabelas, infográficos) e os mistos (constituídos de material verbal e não verbal, como reportagem, propaganda, manual de instrução ilustrado). É possível concluir que se, ao longo da escolaridade, o aluno for exposto apenas à leitura de textos literários, por exemplo, nunca terá oportunidades de ler um texto misto ou um texto não contínuo. Deve, portanto, realizar atividades de leitura de gêneros discursivos das esferas literária, jornalística, publicitária, comercial, doméstica, entre outras que possam interessar.

Relações lógico-semânticas que se estabelecem entre partes do texto, efeitos de sentido decorrentes de escolha vocabular, recursos expressivos de natureza variada e elementos de coesão textual também merecem atenção nas atividades de leitura. O desafio para o professor se coloca na necessidade de elaborar atividades de leitura que compreendam aspectos sociocomunicativos do gênero, temáticos, linguísticotextuais e estilísticos, culminado em uma apreciação crítica da leitura, como propõe uma abordagem sociocognitiva de leitura.

A Prova Brasil não cobra posicionamento crítico do leitor como exigido nos níveis de proficiência 5 e 6 do PISA. Nesse aspecto, as exigências da Prova Brasil não contemplam todo o percurso de leitura esperado de um leitor proficiente. Mesmo estudantes mais jovens precisam ser estimulados à avaliação crítica de suas leituras, a partir de critérios pertinentes ao gênero discursivo alvo de cada leitura. Habilidades necessárias a esse procedimento final da leitura deveriam estar previstas na Matriz de Referência da Prova Brasil. Os níveis 5 e 6 do PISA fazem referências explícitas à necessidade de avaliação crítica da leitura.

\section{CONCLUSÃo}

Nos Parâmetros Curriculares Nacionais - PCN (BRASIL, 1998) e nas diretrizes da Prova Brasil (BRASIL, 2008), a diversidade de textos a ser contemplada no Ensino Fundamental é prevista pelo trabalho com gêneros discursivos, conceito teórico advindo dos trabalhos do filósofo russo Bakhtin, e assumido como 
fundamentação teórica por esses documentos. Esse conceito também subjaz aos níveis de proficiência da prova de leitura do PISA, embora essa avaliação não se paute por orientações educacionais brasileiras.

Em essência, PISA e Prova Brasil se assemelham por cobrarem competências e habilidades capazes de tirar o aluno do nível da simples decodificação e possibilitar-lhe o nível máximo de inferência e apreciação crítica de textos de circulação das mais diversas esferas sociais. Conclui-se que o trabalho do professor de Língua Portuguesa interessado em práticas de leitura mais promissoras, que atendam às exigências dessas provas, deve ser embasado teoricamente nos estudos sobre gêneros discursivos e sua utilização no ensino.

A formação de um leitor proficiente de gêneros diversos, tais como os mencionados pelos documentos referentes ao PISA e à Prova Brasil, não se dá com atividades de leitura esparsas, nem tampouco por atividades constituídas de um texto e algumas perguntas a serem respondidas após a leitura. Esse tipo de atividade, semelhante às questões das provas, são úteis para a verificação de determinadas habilidades, num momento final de um projeto de leitura ou num momento pontual de avaliação.

O desenvolvimento de habilidades de leitura, no entanto, é resultado de um processo mais longo, que só se realiza por meio de projetos de leitura de gêneros discursivos organizados em sequências didáticas que explorem os gêneros em todos os seus aspectos constitutivos. No decorrer dos vários anos de escolaridade, se o aluno participar de projetos dessa natureza, poderá desenvolver habilidades leitoras para êxito não apenas nas provas externas, como a Prova Brasil e a do PISA, mas também em sua vida pessoal.

\section{REFERÊNCIAS}

ANDRADE, Francisco de; TAVARES, Heliton Ribeiro; VALLE, Raquel da Cunha. Teoria de Resposta ao Item: conceitos e aplicações. 2000. Disponível em:<http://www.custosemedidas.ufsc.br/livroTRI.pdf $>$. Acesso em: 06/06/2011.

BAKHTIN, Mikhail. Estética da criação verbal. São Paulo: Martins Fontes, 1992.

BRASIL. Secretaria de Educação Fundamental. Parâmetros Curriculares Nacionais: terceiro e quarto ciclos do ensino fundamental: língua portuguesa. Brasília: MEC/SEF, 1998.

Ministério da Educação. PDE: Plano de Desenvolvimento da Educação: Prova Brasil: ensino fundamental: matrizes de referência, tópicos e descritores. Brasília: MEC, SEB; Inep, 2008.

CIEGLINSKI, A. Alunos do DF alcançam melhor resultado no Pisa. Disponível em: $<$ http://educacao.uol.com.br/ultnot/2010/12/07/alunos-do-df-alcancam-melhor-resultado-nopisa.jhtm>. Acesso em: 07 jun. 2011.

Alunos brasileiros de escolas públicas ficam atrás em avaliação internacional. Disponível em: $<$ http://educacao.uol.com.br/ultnot/2010/12/07/alunos-brasileiros-de-escolas-publicas-ficam-atrasem- avaliacao-internacional.jhtm>. Acesso em: 07 jun. 2011.

DIONÍSIO, Ângela P. Gêneros multimodais e multiletramento. In: KARWOSKI, Acir M.; GAYDECZKA, Beatriz; BRITO, Karim S. (Orgs.). Gêneros textuais: reflexões e ensino. Palmas-PR: Kaygangue, 2005. p. 159177.

DOLZ, Joaquim; SCHNEUWLY, Bernard. Genres et progression en expression orale et écrite. Eléments de réflexions à propos d'une expérience romande. Enjeux, p. 31-49, 1996.

FARACO, Carlos A. Linguagem E゚ Diálogo: as idéias lingüísticas do círculo de Bakhtin. Curitiba: Criar, 2003.

FIORIN, José Luiz. Introdução ao pensamento de Bakhtin. São Paulo: Ática, 2006.

GOIS, Antonio; PINHO, Angela. PISA: Brasil é reprovado, de novo, em matemática e leitura. 05 dez. 2007. Disponível em: <http://www 1.folha.uol.com.br/folha/educacao/ult305u351481.shtml>. Acesso em: 07 jun. 2011.

INEP. Instituto Nacional de Estudos e Pesquisas Educacionais Anisio Teixeira. PISA 2000: Relatório Nacional. Apresentação. Brasília, 2001. Disponível em:

$<$ http://download.inep.gov.br/download/internacional/pisa/PISA2000.pdf>. Acesso em: 20 nov. 2010. 
Pisa. Disponível em: <http://www.inep.gov.br/pisa-programa-internacional-de-avaliacao-dealunos >. Acesso em: 13 maio 2011.

Pisa 2009- itens. Disponível em: <http://portal.inep.gov.br/internacional-novo-pisa-resultados>. Acesso em: 13 maio 2011.

Marcos referenciais. Disponível em: <http://portal.inep.gov.br/internacional-novo-pisamarcos_referenciais $>$. Acesso em: 13 maio 2011.

. Marcos referenciais. Letramento em leitura. Disponível em:

<http://download.inep.gov.br/download/internacional/pisa/2010/letramento_leitura.pdf $>$. Acesso em: 13 maio 2011.

KOCH, Ingedore G. V. A construção dos sentidos no discurso: uma abordagem sociocognitiva. Investigações, Recife, v. 18, n.2, p. 9-38, 2005.

KOCH, Ingedore V.; ELIAS, Vanda M. Ler e compreender: os sentidos do texto. São Paulo: Contexto, 2006.

LOPES-ROSSI, Maria A. G. Leitura de gêneros discursivos no ensino de Língua Portuguesa. Comunicação apresentada no IX Congresso Brasileiro de Linguística Aplicada - CBLA. Rio de Janeiro, 2011.

MARCUSCHI, Luiz A. Gêneros textuais: definição e funcionalidade. In: DIONÍSIO, A. P.; MACHADO, A. R.; BEZERRA, M. A. (Orgs.). Gêneros textuais e ensino. Rio de Janeiro: Lucerna. 2002. p. 19-36.

Produção textual, análise de gêneros e compreensão. São Paulo: Parábola, 2008.

OEI- Organização dos Estados Ibero-americanos. Brasil está entre os países que mais crescem no Pisa e cumpre meta do PDE. 07 dez. 2010. Disponível em: <http://www.oei.es/noticias/spip.php?article8006>. Acesso em: 07 jun. 2011.

OKADA, Ana. Pisa 2009: Xangai, na China, lidera ranking de leitura entre estudantes; Brasil está em $53^{\circ}$. Disponível em: <http://educaçao.uol.com.br/ultnot/2010/12/07/pisa-2009-china-lidera-ranking-deleitura-brasil-esta-em-53.jhtm>. Acesso em: 07 jun. 2011.

SILVA, Jane Q. G. Gênero discursivo e tipo textual. Scripta, Belo Horizonte, v. 2, n. 4, p. 87-106, $1^{\circ}$ sem. 1999.

TARGINO, Rafael. Pisa 2009: Brasil cresce 16 pontos na nota de leitura em nove anos. Disponível em:<http://educacao.uol.com.br/ultnot/2010/12/07/pisa-2009-brasil-cresce-16-pontos-na-nota-deleitura-em-nove-anos.jhtm>. Acesso em: 07 jun. 2012.

Recebido em 24/01/12. Aprovado em 11/04/12. 